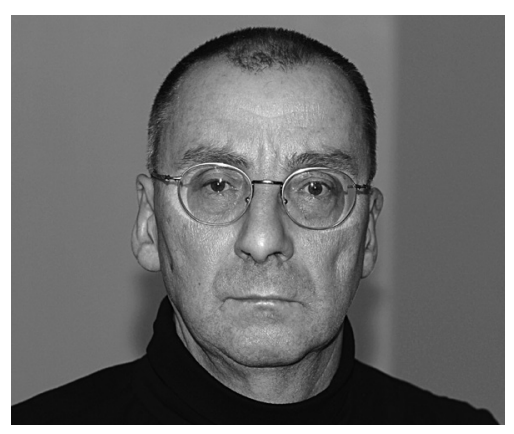

\title{
Geld im System
}

"Wer hat so viel Pinke-pinke, / Wer hat so viel Geld?«, lautet ein nicht nur von Kämmeren gern zitierter Uralt-Schlager der Mainzer Fastnacht. Auch viele Verantwortliche sozialer Organisationen und Unternehmen gestehen - trotz Klagen im eigenen Fall - gelegentlich zu, dass genügend "Geld im System« sei, was soziale Dienstleistungen angehe. Auf rund 80 bis 100 Milliarden Euro schätzt Bernd Halfar Katholischen Universität Eichstätt-Ingolstadt in seinem Einleitungsbeitrag in diesem Heft das Branchenvolumen der Sozialwirtschaft in Deutschland. Und es fließe immer mehr Geld in die Sozialarbeit, die Branche wachse und wachse, es würden immer mehr Mitarbeitende beschäftigt, der Anteil der Steuerfinanzierung an den Gesamtausgaben wachse, weil auch bei der Sozialversicherung der Anteil der "Staatsfinanzierung « demografisch bedingt zunähme und die vereinbarten Qualitätsstandards kontinuierlich angehoben würden. Alle wüssten, dass die Finanzierung des Sozialwesens überprüft werden müsse. Er stellt für den dazu anstehenden Diskurs elf politische und wirtschaftliche Kriterien zur Diskussion. Welche neuen Wege bei der Finanzierung die einzelne Organisation beschreiten kann, beschreibt der frühere Abteilungsleiter der Bank für Sozialwirtschaft Berthold Becher in seinem Beitrag: Mit »Community Bonds" kann insbesondere die Investitionsfinanzierung, mit "Social Impact Bonds « die Finanzierung von Dienstleistungen auf neue Pfeiler gestellt werden. Mit dem damit zusätzlich mobilisierten privaten Kapital können Wachstum und Innovationen von sozialen Organisationen und Sozialunternehmen ermöglicht sowie die Leistungserbringung und die Angebotsstruktur verbessert werden. 